\title{
KAP on Haemostasis and Usage of Styptics Among Dental Students
}

\author{
Nurul Husniyah Binti Che Soh ${ }^{1}$, Dhanraj Ganapathy² and Revathi Duraiswamy ${ }^{3}$ \\ ${ }^{1}$ Saveetha Dental College and Hospitals Saveetha Institute of Medical \\ and Technical Sciences Saveetha University Chennai, India \\ ${ }^{2}$ Professor Et Head Department of Prosthodontics Saveetha Dental College and Hospitals \\ Saveetha Institute of Medical and Technical Sciences Saveetha University Chennai, India \\ ${ }^{3}$ Senior Lecturer Department of Prosthodontics Saveetha Dental College and Hospitals \\ Saveetha Institute of Medical and Technical Sciences Saveetha University Chennai, India
}

\section{ABSTRACT}

Control of bleeding is one of the most common problems faced during a clinical procedure in both minor and major surgery. Haemostasis is a paramount importance during clinical procedures and usage of hemostatic agents are now being commonly used in uncontrolled or excessive bleeding. These agents act to halt bleeding by means of either mechanically or coagulation action. The purpose of this study was to assess the knowledge, awareness and practices on haemostasis and usage of styptics among dental students. A survey was conducted amongst the undergraduate students in a University hospital. A total of 100 responses were obtained from the students. Results were analysed and compared using the SPSS Statistical Software by doing both the frequency tests and correlation tests. This study showed that $46 \%$ of the participants found hemorrhage was very common throughout their clinical practices. Based on their knowledge, $33 \%$ of the students agreed that vasoconstriction is the main action of styptics and $71 \%$ participants were familiar with haemostatic agents. In regard to their clinical practice, $29 \%$ of the participants agreed that it is necessary to use haemostatic agents to arrest bleeding. Overall, $80 \%$ of the participants agreed that more knowledge about haemorrhage and its effective management is necessary in the future.

KEY WORDS: HAEMOSTASIS, HAEMOSTATIC AGENT, HAEMORRHAGE, STYPTIC, THROMBIN.

\section{INTRODUCTION}

Bleeding or haemorrhage is a normal incidence that may take place during or following a surgery. Control of haemorrhage is one of the challenging situations dentists confront during any clinical procedures. Uncontrolled bleeding is a harm as it leads to serious life threatening

\section{ARTICLE INFORMATION}

*Corresponding Author: dhanraj@saveetha.com

Received 4th Aug 2020 Accepted after revision 26th Sep 2020

Print ISSN: 0974-6455 Online ISSN: 2321-4007 CODEN: BBRCBA

Thomson Reuters ISI Web of Science Clarivate Analytics USA and Crossref Indexed Journal

\section{Clarivate
Analytics}

NAAS Journal Score 2020 (4.31) SJIF: 2020 (7.728)

A Society of Science and Nature Publication,

Bhopal India 2020. All rights reserved.

Online Contents Available at: http//www.bbrc.in/

Doi: http://dx.doi.org/10.21786/bbrc/13.8/155 consequences. Furthermore, bleeding may compromise the visibility and possibly the entire procedure itself. Bleeding occurs when a vessel is cut, traumatized or injured during surgery. In most of the cases, applying pressure to the bleeding site alone is enough to achieve haemostasis. The bleeding can either originate from hard tissue or soft tissue such as bone and mucosa. Bleeding can be categorized as arterial, venous or capillary bleeding according to the type of vessel affected in an injury (Ogle, Swantek and Kamoh, 2011).

The bleeding source can be recognized by proper illumination, adequate retraction and comprehensive suctioning. Haemorrhage following minor oral surgical procedure can be categorized into primary haemorrhage, reactionary haemorrhage and secondary haemorrhage. 
This classification is in relation to the period of bleeding induced. Primary haemorrhage occurs during surgery, reactionary haemorrhage two to three hours following the procedure due to halt of vasoconstriction and secondary haemorrhage take place up to 14 days after the surgery mostly due to infection. Haemostasis process involves three major steps that are vasoconstriction, formation of platelet plug and coagulation, secondary hemostasis (Themes, 2016).

When there is damage to the blood vessels, immediate constriction occurs as a result of released vasoconstrictive paracrine by the endothelium cells. This happens because of impermanent reduction of blood flow in the injured blood vessels. This process is known as vasoconstriction. Following this, formation of a platelet plug occurs as a result of plug forms as platelets adhere to the collagen site that has been exposed in the injured endothelial. This is later activated and releases cytokines such as serotonin, thromboxane A2, and endothelin 1 in the injured region. Platelet factors (adenosine diphosphate, fibronectin, thrombospondin, fibrinogen, and platelet derived growth factor) buttress the process of vasoconstriction and greater number of platelets adhere to one another, platelet aggregation and forming platelet plug at the injured site. Coagulation cascade occurs at the same time and ends as fibrin polymer in which helps in the platelet plug stabilization, thus forming blood clot. Secondary haemostasis or clotting cascade can be further classified into intrinsic and extrinsic pathways (Mani et al., 2018).

Minimizing blood loss in the operating field is a key factor during clinical practices as even the smallest amount of bleeding can compromise vision and affect the expected result of a treatment. The outcome may be affected when poor view is associated with haemorrhage. In order to reduce the rate of postoperative haemorrhagic events, various haemostatic agents are used widely in dentistry to achieve optimum outcome (Galanakis, Vasdev and Soomro, 2011). Haemostatic agent or antihaemorrhagic is a substance that promotes haemostasis, stops bleeding (Mani et al., 2018). An ideal haemostatic agent must be effective as well as biocompatible to be used in the body in addition to affordable. Local haemostatic agents can be classified as passive and active haemostatic agents (Kamoh and Swantek, 2012).

Passive haemostatic agents are mostly used as first line agents as they are certainly obtainable, special storage is not needed in addition to low cost. It can be used in heavier bleeding due to its absorption capability and its fibrous/dense structures making them as bigger mass (Brodbelt et al., 2002). It is recommended to be used in less amount as it is able to expand many times than their original mass when they come in contact with fluids. Once haemostasis has been achieved, the agent needs to be removed as it can compress the surrounding structures like nerves and vessels. Examples of passive haemostatic agents are collagens, cellulose, gelatines, and polysaccharide spheres (McCarthy, 2009). Active haemostatic agents involved in clot formation. Examples are thrombin and those product formulations in which thrombin is combined along with a passive agent to provide an active product. It is beneficial in patients on antiplatelet or anticoagulation medications and usually used with gelatin foam.

Most haemostatic agents are contraindicated in contaminated wounds (McCarthy, 2009)(Samudrala, 2008). A styptic is a type of haemostatic agent that acts by tissue contraction in order to seal injured blood vessels. They are also known as local hemostatics. Examples of styptics include aluminum solutions. When it is applied locally, it causes hemostasis by contracting tissue to seal injured blood vessels (Mani et al., 2018). Styptic or haemostatic pencil is a short stick of medication in which Anhydrous aluminium sulfate is the main ingredient, and acts as a vasoconstrictor to halt the blood flow. It is applied directly onto the bleeding region and initiates local vasoconstriction by its astringent chemical that promotes flocculation of the blood (Dorland, 2011).

Previously our department has published extensive research on various aspects of prosthetic dentistry ('Evaluation of Corrosive Behavior of Four Nickelchromium Alloys in Artificial Saliva by Cyclic Polarization Test:An in vitro Study', 2017; Ganapathy, Kannan and Venugopalan, 2017; Jain, 2017a, 2017b; Ranganathan, Ganapathy and Jain, 2017; Ariga et al., 2018; Gupta, Ariga and Deogade, 2018; Anbu et al., 2019; Ashok and Ganapathy, 2019; Duraisamy et al., 2019; Varghese, Ramesh and Veeraiyan, 2019), this vast research experience has inspired us to research about various methods practiced and general knowledge of halitosis among dental students. The main purpose of this study being that by determining the frequently practiced methods in management of hemorrhage and a better insight on the degree of understanding of homeostasis and use of haemostatic agents.

\section{MATERIAL AND METHODS}

Study Setting: This cross-sectional study was done among undergraduate students (includes third years, final years, interns) of Saveetha Dental College and Hospitals. A total of 100 students participated in this study. Study subjects a total of 100 students participated in this study of which 36 were third years, 14 were final years and the remaining 50 were interns.

Methodology: A survey was conducted through an online standard questionnaire with 10 multiple choice questions sent via a Google Form application. The questionnaire consisted of questions about the knowledge, awareness and practices regarding haemostasis and usage of styptics among dental students throughout clinical practices. Adequate time was provided to fill the questionnaire. The responses of the students were recorded, analysed, checked for completeness and were taken up for assessment.

Statistical Analysis: After data was collected and coded, the statistical analysis was done using IBM SPSS 
Statistical Software package (Version 23.0). All the frequency tests were carried out and the Chi-square test was done at a significance level.

Graph 1: Pie chart showing responses to the question among undergraduates based on their year of study. $50.0 \%$ of the respondents were interns. $14.00 \%$ of the respondents were final year undergraduate students. $36.0 \%$ of the respondents were third years.

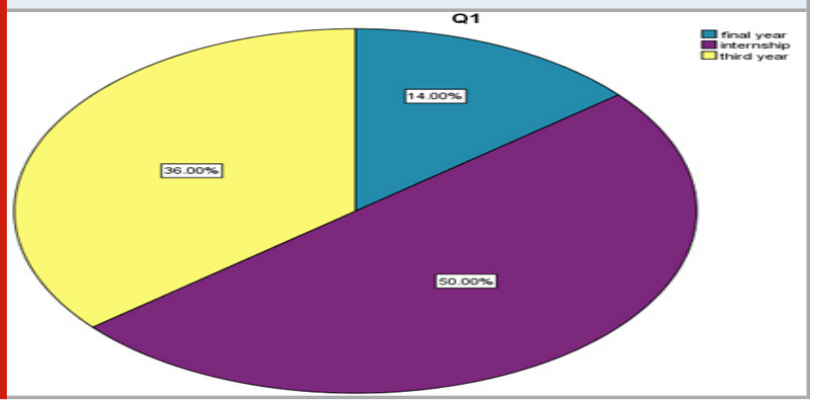

Graph 2: Pie chart showing responses to the question "Do you know what is haemostasis?". 96.0\% of the respondents were acknowledged and $4.00 \%$ were not.

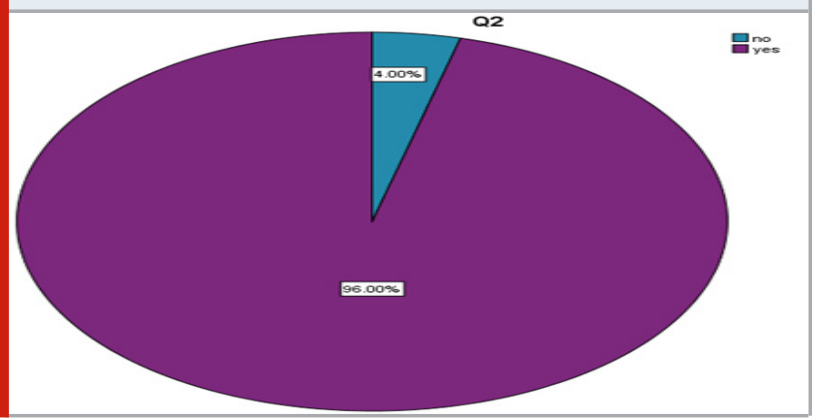

Graph 3: Pie chart showing responses to the question "Are you familiar with haemostatic agent?". 71.0\% of the respondents had an insight regarding antihemorrhagic agent while $29.00 \%$ were not.

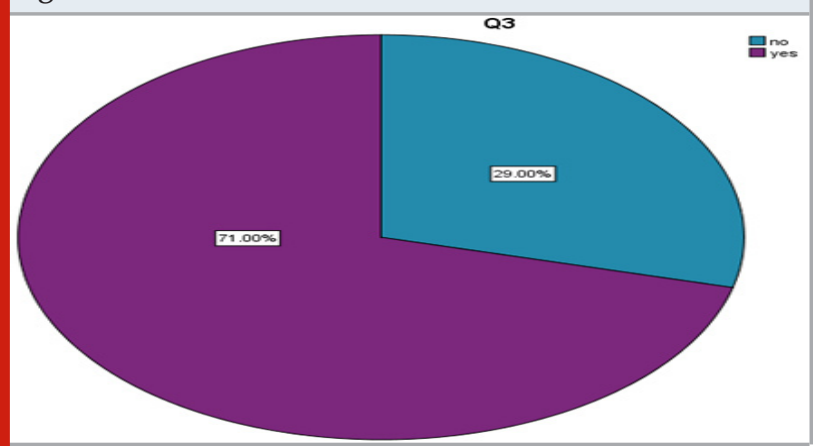

\section{RESULTS AND DISCUSSION}

A total of 100 students participated in the study, 36\% were third years, $14 \%$ were final years and the remaining $50 \%$ were interns [Graph 1]. When inquired about haemostasis, $96 \%$ of the participants were aware about the possibility of haemostasis in clinical practice while 4\% did not [Graph 2]. Assessment on familiarity with haemostatic agents gave the following results, $71 \%$ of the participants acknowledged the use of haemostatic agents whereas $29 \%$ were not [Graph 3]. When questioned about knowledge regarding which type of styptics classification, $60 \%$ of the students recognized that styptics are local haemostatic agents, while remaining chose inorganic, 20\%, organic, 15\% and systemic, 5\% [Graph 4].

Graph 4: Pie chart showing responses to the question "What type is styptics?". 60.0\% of the respondents acknowledged that styptic is a local haemostatic agent, $20 \%$ chose inorganic, 15\% organic and 5 agreed it is a systemic haemostatic agent

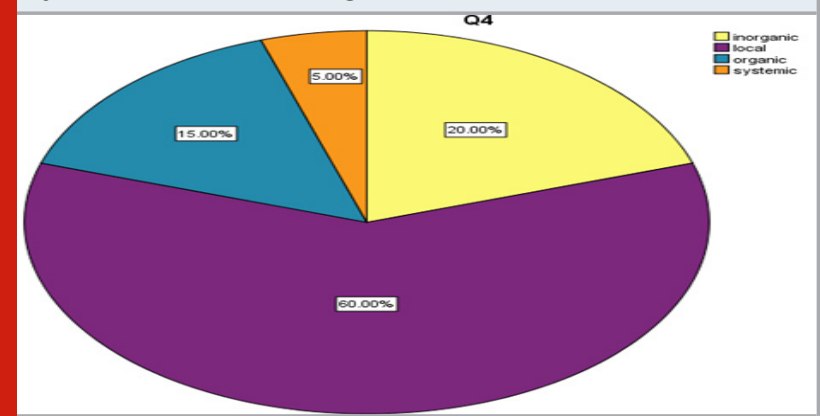

Graph 5: Pie chart showing responses to the question "Are you aware of the use of styptics in dentistry?". 87.0\% of the respondents recognized the use of styptics in dentistry while $13.00 \%$ were not.

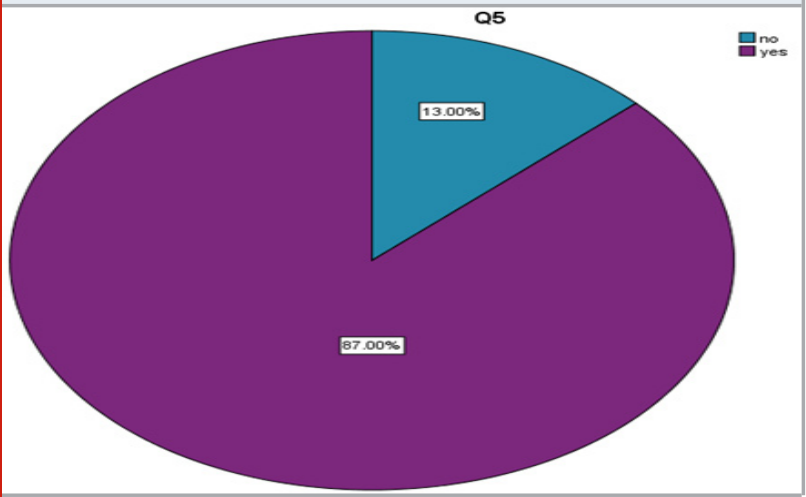

Graph 6: Pie chart showing responses to the question, "Based on your experience, have you encountered patients with profuse bleeding?". 46.0\% of the respondents commonly encountered haemorrhage among dental patients. $30.0 \%$ of the respondents stated that the excessive bleeding is rare and $24.9 \%$ of the respondents never encountered excessive haemorrhage during clinical procedures.

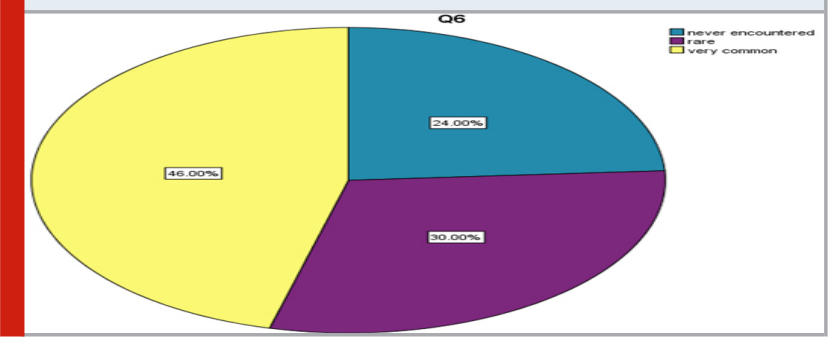


About 87\% participants were aware and 13\% did not acknowledge the use of styptics in dental practice [Graph 5]. Assessment on their personal experience of the occurrence of haemorrhage in patients while doing treatment gave the following results, $46 \%$ agreed that it was very common, $30 \%$ have admitted that it was rare and 24\% has never encountered such an experience [Graph 6]. On the other hand, when inquired about their knowledge on which method is preferable to arrest bleeding, 57\% believed applying pressure works efficiently, 37\% agreed with the use of haemostatic agents while only $6 \%$ not sure the best method to achieve haemostasis [Graph 7].

Graph 7: Pie chart showing responses to the question, "Which method do you think is the most successful to arrest bleeding?". 57.0\% of the respondents commonly applied pressure to achieve haemostasis, $37.0 \%$ of the respondents stated preferred to use haemostatic agents and $6.00 \%$ were not sure how to stop bleeding efficiently.

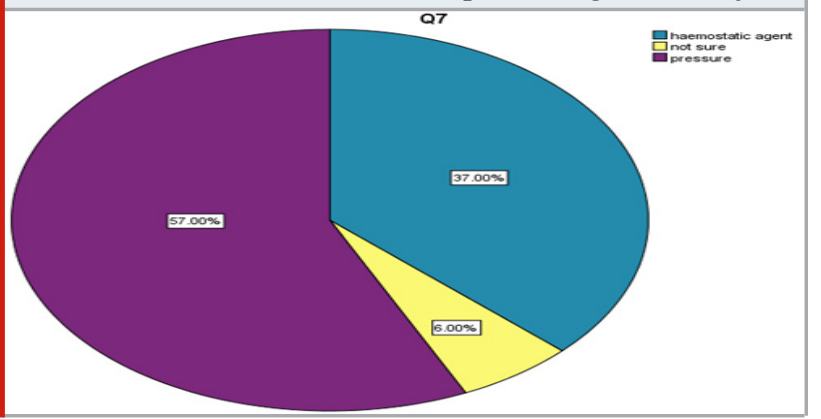

Graph 8: Pie chart showing responses to the question, "Do you think it is necessary to use haemostatic agents to arrest bleeding in all cases?". 54.0\% of the respondents disagree to use haemostatic agents in all cases, $29 \%$ preferred to use while $17.0 \%$ were not sure if it is necessary to use anti-haemorrhagic agents in haemorrhage patients.

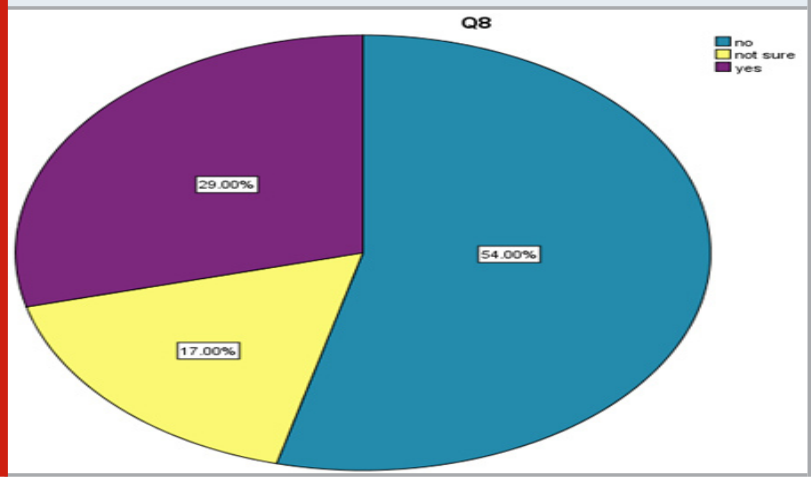

Assessment on the necessity to use haemostatic agents to arrest bleeding in all cases, 29\% agreed that using haemostatic agents help to arrest bleeding, 54\% believed that it is not required to use styptics in all cases while $17 \%$ of the participants were not sure [Graph 8]. Based on their own experience on haemostasis, 39\% preferred to use the agents following surgical extraction and 61\% favoured to use in emergency situations [Graph 9]. 73\% were not aware that some haemostatic agents can cause allergy reactions while $27 \%$ acknowledge the possibility of anti-haemorrhagic tools to cause such reactions [Graph 10]. Moreover, when questioned on action of styptics to achieve haemostasis, 33\% acknowledged it is by vasoconstriction, 41\% chose coagulation and 26\% of the students were not sure [Graph 11]. A majority of the participants, 80\% believed that more knowledge on haemostasis and use of anti-haemorrhagic agents to control bleeding is necessary [Graph 12].

Graph 9: Pie chart showing responses to the question, "When do you think preferable to use haemostatic agents?". $39.0 \%$ of the respondents preferred to use in surgical extraction and $61.0 \%$ preferred in emergency cases.

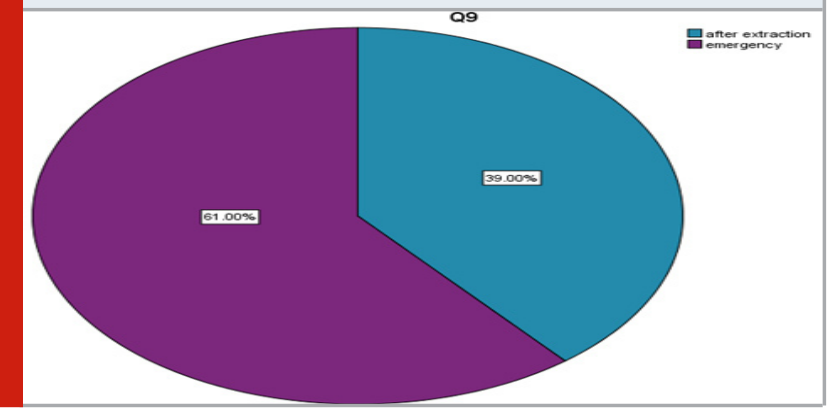

Graph 10: Pie chart showing responses to the question, "Do you aware that haemostatic agents can cause allergy reactions?". 73.0\% of the respondents did not acknowledge while $27.0 \%$ aware the possibility of antihemorrhagic agents to cause allergic reactions.

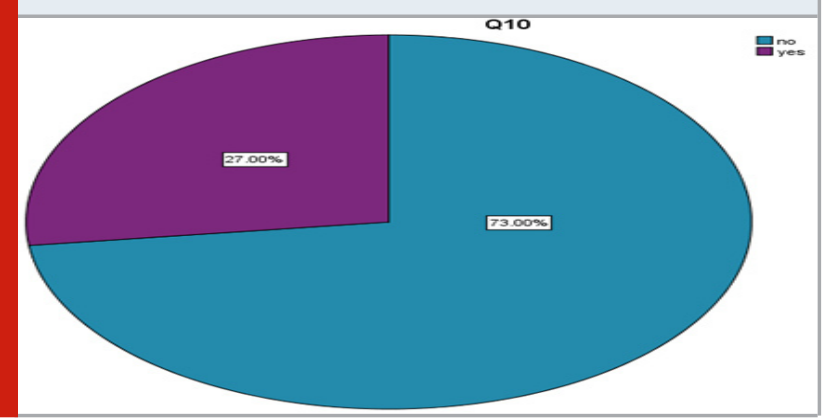

Graph 11: Pie chart showing responses to the question, "Action of styptics to achieve haemostasis?". 33.0\% agreed it is by vasoconstriction, $41.0 \%$ chose a coagulation process while $26.0 \%$ of the respondents were not aware.

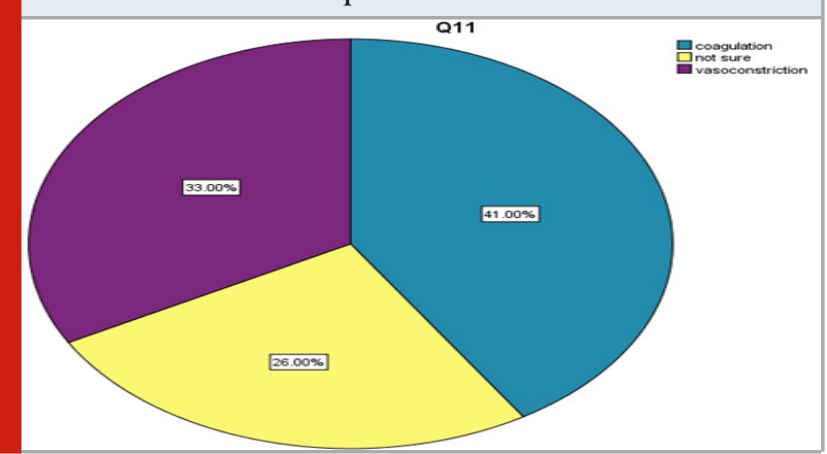


Graph 12: Pie chart showing the responses to the question "Is more knowledge on haemostasis and use of styptics to manage bleeding is necessary?". $80.0 \%$ of the respondents confirmed that they need more knowledge regarding haemostasis and use of styptics in management of haemorrhage. $20.0 \%$ respondents stated that they are well aware about haemorrhage and its management.

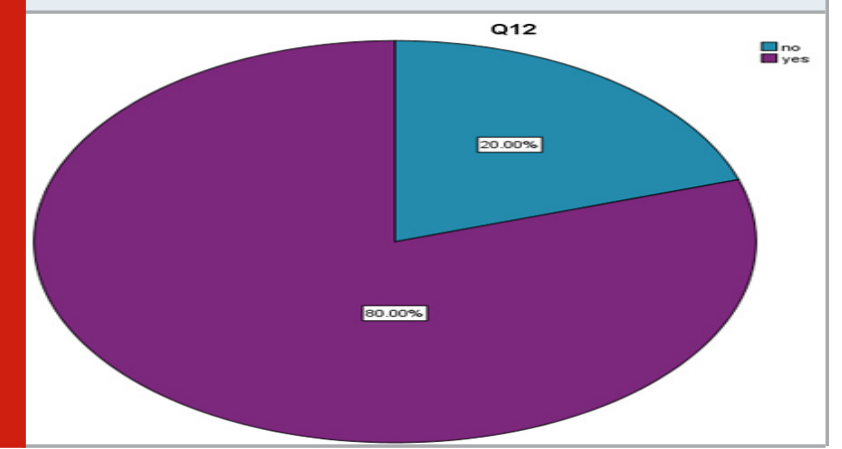

This cross-sectional study was used to assess the knowledge, awareness and practices on haemostasis and usage of styptics among students of Saveetha Dental College. Majority of the participants experienced profuse bleeding in patients while doing treatment. This study is justified by a study done by Gill et al. where haemorrhage was found in patients (Gill et al., 2007). In regard to use of haemostatic agents to arrest bleeding, some participants preferred the use of these agents to control bleeding. This finding is not rare as a wide variety of haemostatic tools have been used in management of haemorrhage in a study performed by Galakani et al. (Galanakis, Vasdev and Soomro, 2011). Based on this study, most participants agreed that the use of haemostatic agents should be implemented only in emergency cases. Galakani et al. recognized that hemostatic agents and tissue sealants should not be considered as a surgical alternative technique, but rather as a tool to assist and achieve the optimal surgical outcome (Rosenstiel, Land and Fujimoto, 2006).

In this study, most participants were familiar with the use of haemostatic agents. This is not a rare finding as chemical haemostatic agents such as Rosenstiel et al. and Mohaan et al. employed the use of aluminium chloride, $\mathrm{AlCl} 3$ and ferrous sulphate have been used to arrest more serious haemorrhage from cut capillaries and arterioles (Rosenstiel, Land and Fujimoto, 2006) (Mohan et al., 2011). A majority of the participants acknowledged that styptics work by vasoconstriction and are helpful to arrest haemorrhage. Weir et al. recognized the use of aluminium sulphate as haemostatic agents in restorative dentistry as alum can be used as a substitute for epinephrine because it is safer and has lesser systemic effects (Weir and Williams, 1984).

\section{CONCLUSION}

Knowledge on usage of haemostatic agents are necessary among dental practitioners as bleeding during and postoperative procedures are common in clinical practices.
As local haemostatic agents are effective in controlling bleeding during oral surgical procedures in individuals with congenital and acquired bleeding disorders as well as in patients who are on antithrombotic medications for their systemic conditions, thus the agents should be made available in clinical institution to avoid harm to patients and help in achieving optimum treatment required.

\section{ACKNOWLEDGEMENTS}

Nil

\section{Conflict of Interest: Nil}

\section{REFERENCES}

Anbu, R. T. et al. (2019) 'Comparison of the Efficacy of Three Different Bone Regeneration Materials: An Animal Study', European journal of dentistry, 13(1), pp. 22-28.

Ariga, P. et al. (2018) 'Determination of Correlation of Width of Maxillary Anterior Teeth using Extraoral and Intraoral Factors in Indian Population: A Systematic Review', World Journal of Dentistry, 9(1), pp. 68-75.

Ashok, V. and Ganapathy, D. (2019) 'A geometrical method to classify face forms', Journal of oral biology and craniofacial research, 9(3), pp. 232-235.

Brodbelt, A. R. et al. (2002) 'Intraspinal oxidised cellulose (Surgicel) causing delayed paraplegia after thoracotomy--a report of three cases', Annals of the Royal College of Surgeons of England, 84(2), pp. 97-99.

Dorland (2011) Dorland's Illustrated Medical Dictionary. Elsevier Health Sciences.

Duraisamy, R. et al. (2019) 'Compatibility of Nonoriginal Abutments With Implants: Evaluation of Microgap at the Implant-Abutment Interface, With Original and Nonoriginal Abutments', Implant dentistry, 28(3), pp. 289-295.

Evaluation of Corrosive Behavior of Four Nickelchromium Alloys in Artificial Saliva by Cyclic Polarization Test:An in vitro Study' (2017) World Journal of Dentistry, 8(6), pp. 477-482.

Galanakis, I., Vasdev, N. and Soomro, N. (2011) 'A review of current hemostatic agents and tissue sealants used in laparoscopic partial nephrectomy', Reviews in urology. ncbi.nlm.nih.gov, 13(3), pp. 131-138.

Ganapathy, D. M., Kannan, A. and Venugopalan, S. (2017) 'Effect of Coated Surfaces influencing Screw Loosening in Implants: A Systematic Review and Meta-analysis', World Journal of Dentistry, 8(6), pp. 496-502.

Gill, I. S. et al. (2007) 'Comparison of 1,800 laparoscopic and open partial nephrectomies for single renal tumors', The Journal of urology, 178(1), pp. 41-46.

Gupta, P., Ariga, P. and Deogade, S. C. (2018) 'Effect 
of Monopoly-coating Agent on the Surface Roughness of a Tissue Conditioner Subjected to Cleansing and Disinfection: A Contact Profilometric Study', Contemporary clinical dentistry, 9(Suppl 1), pp. S122S126.

Jain, A. R. (2017a) 'Clinical and Functional Outcomes of Implant Prostheses in Fibula Free Flaps', World Journal of Dentistry, 8(3), pp. 171-176.

Jain, A. R. (2017b) 'Prevalence of Partial Edentulousness and Treatment needs in Rural Population of South India', World Journal of Dentistry, 8(3), pp. 213-217.

Kamoh, A. and Swantek, J. (2012) 'Hemostasis in oral surgery', Dental clinics of North America, 56(1), pp. 17-23, vii.

Mani, A. et al. (2018) 'Hemostatic agents in dentistry', Galore International Journal of Health Sciences \& Research. gijhsr.com, 3, pp. 40-46.

McCarthy, J. R. (2009) 'Methods for assuring surgical hemostasis', Rothrock JC, Seifert PC, editors.

Mohan, M. et al. (2011) 'Pharmacological Agents in Dentistry: A Review', Journal of Pharmaceutical Research International. journaljpri.com, pp. 66-87.

Ogle, O. E., Swantek, J. and Kamoh, A. (2011) 'Hemostatic agents', Dental clinics of North America. dental. theclinics.com, 55(3), pp. 433-9, vii.

Ranganathan, H., Ganapathy, D. M. and Jain, A. R. (2017) 'Cervical and Incisal Marginal Discrepancy in Ceramic Laminate Veneering Materials: A SEM Analysis', Contemporary clinical dentistry, 8(2), pp. 272-278.

Rosenstiel, S. F., Land, M. F. and Fujimoto, J. (2006) Contemporary Fixed Prosthodontics. Elsevier Health Sciences.

Samudrala, S. (2008) 'Topical Hemostatic Agents in Surgery: A Surgeon's Perspective', AORN Journal, pp. S2-S11. doi: 10.1016/s0001-2092(08)00586-3.

Themes, U. F. O. (2016) Hemostatic Agents, Pocket Dentistry. Available at: https://pocketdentistry.com/ hemostatic-agents/ (Accessed: 3 July 2020).

Varghese, S. S., Ramesh, A. and Veeraiyan, D. N. (2019) 'Blended Module-Based Teaching in Biostatistics and Research Methodology: A Retrospective Study with Postgraduate Dental Students', Journal of dental education, 83(4), pp. 445-450.

Weir, D. J. and Williams, B. H. (1984) 'Clinical effectiveness of mechanical-chemical tissue displacement methods', The Journal of prosthetic dentistry, 51(3), pp. 326-329. 